\title{
Da Revolução Verde à agrobiotecnologia: ruptura ou continuidade de paradigmas?
}

\author{
Leide Albergoni ${ }^{1}$ \\ Victor Pelaez ${ }^{2}$
}

Resumo: A Revolução Verde pode ser caracterizada como um paradigma tecnológico derivado da evolução dos conhecimentos da química e da biologia, que definiram uma trajetória tecnológica baseada no uso intensivo de insumos químicos (fertilizantes e pesticidas). A partir da década de 1970, esse modelo passou a apresentar sinais de esgotamento cristalizados na identificação dos problemas ambientais ocasionados pelo uso intensivo de agrotóxicos e nos próprios limites de crescimento da indústria de insumos químicos. O desenvolvimento da biotecnologia possibilitou o surgimento de técnicas capazes de superar as barreiras genéticas existentes nas técnicas de melhoramento tradicional. Se por um lado essa mudança significou a possibilidade de superação dos limites alcançados pelo modelo tecnológico da Revolução Verde, ela representou, por outro lado, a oportunidade de diversificação de atividades das empresas do ramo químico. A questão que se coloca é se essa oportunidade tecnológica está sendo explorada para a construção de um novo modelo tecnológico baseado na redução do uso de insumos químicos, ou se está representando uma continuidade da trajetória do paradigma anterior, a partir de uma estratégia de valorização de ativos das empresas do ramo químico.

Palavras-chave: Revolução Verde; biotecnologia; paradigmas tecnológicos.

1 Professora do Centro Universitário Franciscano do Paraná - UniFae.

2 Professor Adjunto do Departamento de Economia da UFPR. 


\title{
From the Green Revolution to agrobiotechnology: paradigm rupture or continuity?
}

\begin{abstract}
The Green Revolution can be seen as a technological paradigm originated from developments in chemistry and biology, determining a technological path of extensive use of chemical inputs (fertilizers and pesticides). Since the 1970's, the limits of the Revolution have become apparent, especially with the identification of environmental problems caused by chemical residues and the growth limits of the chemicals industry. Developments in biotechnology have led to techniques that overcome genetic barriers found by traditional techniques. If, on the one hand, such change has led us beyond the limits of the Green Revolution, on the other hand it allowed the diversification of firms in the chemicals industry. The point discussed here is whether this new technology will reduce the use of chemical inputs or simply resume the old paradigm with new tools, under an industry strategy of increasing the value of its assets.
\end{abstract}

Key words: Green Revolution; biotechnology; technological paradigms.

JEL: O14; O33

\section{Introdução}

Apoiada em uma promessa de aumento da oferta de alimentos que proporcionaria a erradicação da fome, a Revolução Verde resultou em um novo modelo tecnológico de produção agrícola que implicou na criação e no desenvolvimento de novas atividades de produção de insumos (químicos, mecânicos e biológicos) ligados à agricultura. Esse modelo produtivo passou, no entanto, a apresentar limites de crescimento a partir da década de 1980, com a diminuição do ritmo de inovações, o aumento concomitante dos gastos em P\&D e a identificação dos impactos ambientais advindos do uso intensivo desses insumos, em especial dos agrotóxicos.

A possibilidade de exploração comercial da biotecnologia baseada na utilização da engenharia genética parece ter surgido como uma oportunidade de superar esses limites por meio do desenvolvimento de organismos geneticamente modificados (OGM), com maior resistência a determinados agrotóxicos e/ou que substituem o seu uso. Dentro de um contexto internacional de reconhecimento da propriedade intelectual no desenvolvimento de OGM e de uma preocupação crescente com os efeitos adversos desse modelo agrícola, as principais empresas fabricantes de agrotóxicos têm se reestruturado no sentido de promover uma imagem mais ligada ao desenvolvimento de sementes por meio da engenharia genética. A tecnologia do DNA recombinante, ou transgenia, 
permitiu a transferência de genes de um organismo a outro superando as barreiras de cruzamento genético entre as espécies, o que aumentou em muito a produtividade das pesquisas no desenvolvimento de cultivares com características agronômicas consideradas desejáveis. Além da transgenia, a biotecnologia moderna tem se caracterizado pelo desenvolvimento nas áreas da genômica e da proteômica, por meio das quais busca-se conhecer a complexidade do conjunto dos genes de um organismo e como estes se expressam e interagem a partir de redes funcionais que se estabelecem entre as proteínas. $O$ fato de as empresas do ramo químico-farmacêutico terem diversificado as suas atividades para o ramo de sementes, privilegiando o desenvolvimento de novos produtos a partir da transgenia, acaba muitas vezes por adotar o termo biotecnologia como sinônimo de transgenia. Vale ressaltar, nesse sentido, a importância estratégica vislumbrada por essas empresas no uso da tecnologia do DNA recombinante, que permite não apenas um aumento considerável do ritmo de obtenção de novas cultivares, como também um aumento da eficiência da cobrança dos direitos de propriedade intelectual. Essa apropriação é particularmente importante em países como o Brasil, aonde é reservado aos agricultores o direito de usar parte da sua produção como sementes. Neste caso, o reconhecimento no Brasil da patente de processo de obtenção vegetal por meio da transgenia garante a essas empresas a cobrança de royalties aos agricultores. Seguindo uma lógica Penroseana, as estratégias de diversificação dessas empresas indicam que a recombinação de seus recursos produtivos associa-se sobretudo às possibilidades de recombinação dos organismos vivos no sentido de gerar novas oportunidades de crescimento.

A questão que se coloca é se a biotecnologia agrícola, notadamente a transgenia, poderia estar rompendo com o paradigma da Revolução Verde - modificando as práticas de produção baseadas no uso intensivo de agrotóxicos - ou se estaria representando simplesmente uma continuidade, ao viabilizar uma revalorização de seus principais ativos ligados à produção de agrotóxicos. Dito de outra forma, a agrobiotecnologia baseada na engenharia genética faz parte de uma nova trajetória tecnológica de redução, ou até mesmo de eliminação dos insumos químicos utilizados, ou representa a continuidade da trajetória desenvolvida na Revolução Verde?

O objetivo deste trabalho é a comparação do modelo tecnológico adotado a partir da Revolução Verde com o representado pela biotecnologia agrícola, apontando os elementos de mudança e de continuidade nas formas de solução dos problemas produtivos. Esse tipo de análise considera a inovação tecnológica como um processo de formulação e de solução de problemas produtivos que se constitui e se transforma tanto em função de uma dinâmica interna de aquisição do conhecimento quan- 
to em função de uma dinâmica externa de acumulação de capital. Para tanto, será utilizado como instrumental de análise o referencial neoschumpeteriano que discute a dinâmica do progresso técnico a partir dos conceitos de paradigma e de trajetória tecnológica.

Apesar de a Revolução Verde ser caracterizada fundamentalmente pela combinação de insumos químicos (fertilizantes, agrotóxicos), mecânicos (tratores e implementos) e biológicos (sementes geneticamente melhoradas), este trabalho enfatiza sobretudo as trajetórias tecnológicas associadas aos insumos químicos (agrotóxicos) e biológicos, cuja combinação técnica e econômica consiste em nosso foco de análise. Nesse contexto, vários autores enfatizam a importância relativa do melhoramento genético vegetal para o sucesso da Revolução Verde. Dayrubinstein e Heisey (2006, p. 51), ao discutirem as contribuições dos recursos genéticos na evolução tecnológica da agricultura, ressaltam que:

(...) the Office of Technology Assessment (1987) estimated that genetic improvements have accounted for half the yield gains in major cereal crops since the 1930s. Thirtle (1985) estimated the contributions of biological advances to U.S. crop production, controlling for changes in other inputs such as fertilizers, machinery, and pesticides, and concluded that biological improvements contributed to 50 percent of the yield growth of corn, 85 percent ofr soybeans, 75 percent for wheat, and 24 percent for cotton. Duvick (2005) estimated that 50 percent of the increases in maize (corn) yields since the early 1930's have been due to breeding. To date, practically all published economic analyses of the collection of genetic material, conservation in gene banks, or use of genetic resources in plant breeding programs have shown significant economic benefits from these activities.

Este artigo apresenta inicialmente (seção 2) uma breve revisão conceitual da análise neoschumpeteriana dos paradigmas e das trajetórias tecnológicas, com ênfase nos elementos que representam as possibilidades de continuidade e de ruptura dos modelos técnico-econômicos de produção. A seção 3 resgata a evolução da indústria de agrotóxicos em termos de seu ritmo de desenvolvimento tecnológico e de seus entraves que levaram à reestruturação das principais empresas desse ramo de atividade. A seção 4 apresenta as estratégias de diversificação dessas empresas no ramo de sementes, com o intuito de ilustrar a interdependência das duas trajetórias tecnológicas associadas ao desenvolvimento de sementes geneticamente modificadas e de agrotóxicos. 


\section{Inovações tecnológicas e mudança de paradigmas}

Na perspectiva schumpeteriana, o processo concorrencial ocorre não apenas em função da maximização dos lucros, mas da própria sobrevivência e permanência da firma no mercado. Para tanto, a firma deve procurar adquirir vantagens competitivas por meio de novas mercadorias, novas tecnologias, novas fontes de oferta e novos tipos de organização. Nessa busca por vantagens competitivas, a firma é uma organização que influencia o ambiente em que atua por meio de inovações sejam elas tecnológicas, mercadológicas, organizacionais ou institucionais. Esse processo concorrencial traduz-se em mudanças estruturais que são verificadas no surgimento de novas demandas, novos hábitos dos consumidores e novas formas de se organizar a produção (Ferrari \& Paula 1999).

As inovações introduzidas por uma firma podem ser incrementais ou radicais. Inovações incrementais são aquelas que derivam de melhorias em produtos e em processos já existentes. Inovações radicais, por sua vez, são inovações de produtos ou de processos que não têm como antecedente melhorias de produtos e de processos existentes. Seria o caso do nylon, que não poderia ter surgido a partir de melhoramentos na indústria de lã, ou ainda da energia nuclear, que não poderia ter emergido de melhoramentos incrementais nas estações de carvão ou de petróleo. Essas inovações radicais são frutos de atividade deliberada de P\&D das empresas, universidades ou centros de pesquisa governamentais. Elas aumentam a produtividade e trazem novos produtos e materiais. Seu impacto econômico pode ser, no entanto, localizado ou restrito a alguns setores, não implicando em mudanças fundamentais no conjunto das organizações industriais (Freeman \& Perez 1988).

Por outro lado, a introdução de um conjunto de inovações radicais e incrementais, com um efeito em toda a economia de forma direta ou indireta, constitui uma mudança de paradigma tecnológico ou revolução tecnológica. As mudanças envolvidas vão além da trajetória da engenharia para um processo ou produto: afetam os custos de insumos e as estrutura de produção e de distribuição de mercadorias (Freeman \& Perez 1988).

Paradigma tecnológico é definido como o "padrão" ou "modelo" de princípios derivados de conhecimentos das ciências naturais e da tecnologia existente, o qual define o campo de investigação, os problemas a serem resolvidos e os procedimentos para resolvê-los. Um paradigma tecnológico possui um poderoso efeito de exclusão: os esforços de pesquisa são relativamente focados em um caminho tecnológico, fechando-se a outras direções (Dosi 1982). De fato, quando um paradigma tecnológico começa a estabilizar-se, os objetivos e heurísticas da pes- 
quisa técnica geralmente tendem a divergir da investigação puramente científica. De certo modo, "(...) the technologies less directly depend on science." (Dosi 1988:1137).

Dentro de um paradigma tecnológico desenvolvem-se trajetórias tecnológicas, definidas como o padrão da atividade normal de solução de problemas colocados pelo paradigma. A trajetória tecnológica pode ser representada pelo movimento de trocas multidimensionais entre as variáveis tecnológicas definidas como relevantes pelo paradigma. A mudança de um paradigma geralmente implica na mudança da trajetória tecnológica (Dosi 1982, 1988). Uma trajetória pode ser forte ou fraca, restrita ou mais genérica. Geralmente, há complementaridade entre as trajetórias, uma vez que as diferentes formas de conhecimento, experiência e habilidade são inter-relacionadas. Uma trajetória possui uma fronteira tecnológica, definida como o mais alto nível de conhecimento alcançado dentro de um caminho tecnológico com respeito a uma tecnologia economicamente relevante (Dosi 1982).

Um paradigma tecnológico também possui certos limites, estabelecidos por seu ciclo de vida de quatro períodos: i) difusão inicial, quando surgem as inovações radicais em produtos e processos, proporcionando múltiplas oportunidades de novos investimentos e surgimento de novas indústrias e novos sistemas tecnológicos; ii) crescimento rápido (prematuro), quando as novas indústrias vão se firmando e explorando inovações sucessivas; iii) um crescimento tardio, quando o crescimento das novas indústrias começa a desacelerar-se e o paradigma difundese para os setores menos receptivos; iv) fase de maturação, ou a última fase do ciclo de vida do paradigma, na qual os mercados começam a saturar-se, os produtos e processos se padronizam, o conjunto de produtos chegam a um ponto de esgotamento e as inovações incrementais nos processos trazem pouco aumento de produtividade. Nesta última fase, a experiência acumulada em cada indústria e no mercado é tal que cada novo produto alcança a maturidade cada vez mais rápido (Perez 1992).

Quando a última fase do paradigma é atingida, as firmas não permanecem inativas: buscam adotar estratégias que as mantenham no mercado, através de uma vantagem competitiva. Dentre as estratégias possíveis, a busca por novas tecnologias que possibilitem a criação de novos produtos pode provocar uma mudança de tão longo alcance que implica em um novo paradigma tecnológico. "Son precisamente los éxitos sucesivos en esta búsqueda múltiple, empreendida por más y más empresas e industrias a medida que éstas enfrentan los límites de las trayectorias conocidas de innovación en productos y mejoras en procesos, los que finalmente llevan a la conformación gradual del nuevo paradigma." (Perez 1992:26). 
Segundo Perez (1983, 1992:25), um novo paradigma tecnológico surge a partir de esforços de pesquisa de uma indústria que encontra seu limite de crescimento dentro do paradigma vigente, ou seja, como resposta à demanda persistente por tecnologias capazes de superar o limite da trajetória tecnológica baseada no uso de um insumo-chave. De início, os paradigmas coexistem, em uma sobreposição entre a fase de maturidade do paradigma predominante e a "infância" do novo, por meio de um processo de mudança estrutural denominado período de transição.

Os novos paradigmas emergem, portanto, a partir de uma inovação propositalmente introduzida por uma firma, cujo objetivo é obtenção de vantagem competitiva. Uma vez que esta firma realizou investimentos vultosos em pesquisa e desenvolvimento (P\&D), é de seu interesse difundir a tecnologia para recuperar o investimento o mais rápido possível. Neste caso, a transição de um paradigma para outro pode também ser influenciada mais pelo discurso e pelos instrumentos de persuasão que a empresa possui do que por vantagens empiricamente comprovadas. Mesmo porque, na fase pré-paradigmática o desenho do novo produto ainda não está consolidado, o que dificulta a comprovação das vantagens prometidas. A adoção de um novo paradigma pode ocorrer em função das promessas ou expectativas de produção e de rentabilidade vislumbradas.

A consolidação de um paradigma, como um novo modelo prático, passa por um longo período de gestação. "Se introduce en forma de inovaciones aisladas, por ensayo y error en muchos puntos del sistema económico, a menudo como solución a algunas de las limitaciones del antiguo paradigma, a medida que industrias, empresas o países los van enfrentando" (Perez 1992:28).

O novo paradigma está baseado em conhecimentos específicos que o paradigma anterior não tinha acesso (Perez 1992). Assim sendo, a comparação e a avaliação da superioridade de paradigmas tecnológicos pode tornar-se difícil (Dosi 1982, 1988). Neste caso, o papel de fatores econômicos, sociais e institucionais precisa ser considerado na transição de paradigmas. A escolha de um paradigma envolve na realidade a combinação de fatores racionais (avaliação técnica e econômica) e não racionais (imagem, costumes, valores simbólicos, gostos, etc.) (Biondi \& Galli 1992).

Da perspectiva puramente econômica, um novo paradigma surge em um ambiente ainda dominado pelo paradigma anterior e, para consolidar-se, precisa satisfazer três condições: i) redução de custos; ii) crescimento rápido da oferta, explicitando a inexistência de barreiras no longo prazo aos investidores; e iii) apresentar claramente um potencial para uso ou incorporação desta tecnologia em vários processos e produtos dentro do sistema econômico. Se o novo paradigma cumpre essas 
condições, ele prova suas vantagens comparativas. Inicia-se destarte um processo de reestruturação das variáveis-chave até que ele torne-se predominante (Freeman \& Perez 1988).

\section{A Revolução Verde: o desenvolvimento da indústria de insumos químicos}

Desde meados do século XIX, existiam máquinas a vapor substituindo a força humana na agricultura, mas seu uso era limitado pelas barreiras biológicas das lavouras (Goodman \& Redclift 1991). A partir da comprovação empírica, por Justus Von Liebig no final do século XIX, de que a produtividade das plantas era diretamente proporcional à quantidade de insumos químicos colocados no solo, desenvolveu-se uma indústria de fertilizantes sintéticos (potássio, nitrogênio e fósforo), substituindo o uso de fertilizantes naturais (húmus e esterco) na Europa (Goodman et al. 1990; Veiga 1994). Nessa época, importantes lavouras norte-americanas e européias começaram a sofrer grandes danos por fungos e insetos devastadores, o que estimulou a pesquisa em substâncias que eliminassem ou reduzissem esses tipos de pestes (Stetter 1993).

No final do século XIX, a produtividade física das lavouras passou por uma fase de tendência ao declínio. Diversas pesquisas foram iniciadas buscando superar essa tendência, resultando, entre outras, no desenvolvimento do milho híbrido por volta de 1914. A técnica de hibridização surgiu então como um método para aumentar a produtividade (Goodman et al. 1990). A partir da década de 1930, o pacote comercial representado pelo milho híbrido foi difundido nos Estados Unidos (Goodman \& Redclift 1991). As pesquisas de melhoramento genético prosseguiram e foram estendidas a outras culturas, tais como o tomate, a beterraba e o algodão, para as quais foram desenvolvidas variedades resistentes à manipulação mecânica (Goodman et al. 1990).

Ao final da Segunda Guerra Mundial, o modelo tecnológico estava consolidado nos EUA e começou a ser difundido nos demais países ${ }^{3}$. A substituição da agricultura tradicional por uma agricultura moderna nos países de Terceiro Mundo representou a abertura de importantes canais para a expansão dos negócios das empresas que se voltaram à produção de insumos para a agricultura (Beaud 1994; Brum 1988).

O primeiro país subdesenvolvido a adotar o pacote da Revolução Verde foi o México, onde o governo já desenvolvia um programa de pesquisa para melhoramento de trigo e milho desde a década de 1930 (Goodman

3 Já neste período, uma das principais justificativas para a difusão desse modelo de produção agrícola baseava-se no argumento de proporcionar a solução para a erradicação da fome no mundo (Teixeira \& Lages 1996; Goodman \& Redclift 1991). 
\& Redclift 1991). A partir da década de 1960, a pesquisa agrícola adquiriu uma dinâmica internacional. Diversos outros centros de pesquisa (IARCs - International Agricultural Research Centers) foram instalados em vários países, contando com financiamento do Banco Mundial, de fundações sem fins lucrativos como a Fundação Rockefeller e a Fundação Ford, bem como outras instituições de financiamento. Em 1971, foi criado o Consultative Group on International Agricultural Research (CGIAR), a agência de pesquisa que tem dirigido os esforços de pesquisa dos vários centros envolvidos no melhoramento genético (Everson \& Gollin 2002).

Como resultado da adoção desses insumos, a produtividade média dos cereais dobrou em 30 anos, o que significou um aumento de cerca de $7 \%$ no total de alimentos per capta produzidos nos países de Terceiro Mundo (Pretty 1995:30). Por outro lado, os efeitos nocivos das práticas intensivas da Revolução Verde passaram a ser identificados a partir da década de 1960 e divulgados através da mídia e de publicações científicas. A utilização de fertilizantes e de agrotóxicos começou a ser duramente criticada, em função dos problemas causados pelo uso intensivo desses produtos, tais como: intoxicação humana e animal; surgimento de pragas mais resistentes; contaminação da água e do solo; erosão; e salinização do solo (Pimentel 1996; Ilbery \& Bower 1998; Trigo 1994).

Além disso, esse modelo de produção começou a apresentar sinais de esgotamento dos retornos econômicos esperados. Apesar do uso crescente desses insumos, os aumentos da produção agrícola têm sido decrescentes, com uma redução da ordem de 40 vezes no últimos quarenta anos. De uma taxa de incremento da produção (produção marginal) de aproximadamente 50\% no período 1961-1971, esta reduziu-se à metade (25\%) no período 1971-1981, depois a cerca de $15 \%$ entre 19811991, chegando a 12\% no decênio 1991-2001 (Gráfico 1). 
GRÁFICO 1 - TAXA DE INCREMENTO DA PRODUÇÃO AGRÍCOLA - MUNDO

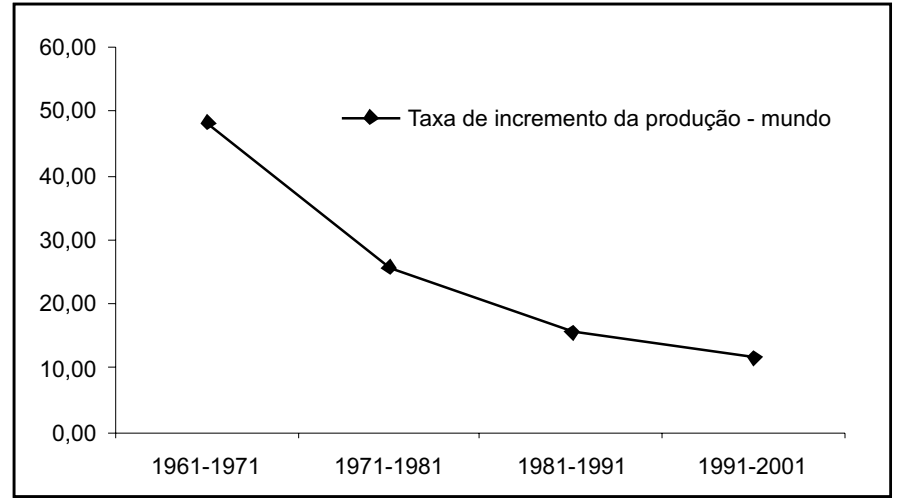

FONTE: FAO. Dados trabalhados.

De 1940 a 1960 a indústria de agrotóxicos passou por sua fase áurea, com o desenvolvimento intenso de ingredientes ativos voltados ao aumento da produtividade e à melhoria no manejo das plantações, por meio do combate de insetos, fungos e ervas-daninhas (Hartneli 1996; Joly \& Lemarie 2002). Após esse período, iniciou-se a fase intermediária da indústria, em que a taxa de introdução de novos ingredientes ativos declinou rapidamente. As estratégias concorrenciais começaram então a orientar-se à redução de custos e à diferenciação de produtos. A competição de custos favorecia a introdução de ingredientes ativos com taxa de dosagem menor, enquanto que a diferenciação, por meio de novas formulações e embalagens, conduzia a produtos mais fáceis de serem aplicados e menos prejudiciais à saúde e ao meio ambiente (Hartnell 1996).

Após a metade da década de 1980 , as patentes dos ingredientes ativos introduzidos durante os anos 60 e 70 começaram a expirar e os produtos ficaram expostos à competição de genéricos. "Differentiation on secondary features, such as formulations and packaging, is the only competitive option when the AIs [Active Ingredients] are the same. Mixtures formulations based on two or more AIs became more prolific." (Hartnell 1996)

Concomitantemente, as pestes resistentes que começaram a aparecer estimulavam o lançamento de novos produtos no mercado. No entanto, a necessidade de sustentabilidade econômica e ambiental, trazida pelos debates em torno dos impactos ambientais da Revolução Verde, limitava esse processo, devido ao aumento dos custos de pesquisa e de comercialização em função das regulamentações ambientais que se tornavam cada vez mais rigorosas (Joly \& Lemarie 2001). 
Começou-se então uma discussão sobre a necessidade de uma agricultura ecológica e sustentável, indicando uma crise do modelo tecnológico da Revolução Verde (Buttel \& Yongberg 1982; Ilbery \& Bowler 1998). Surgiram propostas de práticas alternativas, baseadas na redução ou na eliminação dos insumos químicos e na conservação do solo. Dentre as várias alternativas que se apresentavam, a biotecnologia passou a ser vista como um possível instrumento capaz de viabilizar um novo modelo sustentável. E a engenharia genética passou a ser adotada como um instrumento voltado ao desenvolvimento de novas variedades que dispensassem o uso de pesticidas e fertilizantes. A grande expectativa propalada voltava-se à redução do impacto sobre o meio ambiente, proporcionando, ao mesmo tempo, aumentos de produtividade (Trigo 1994; Veiga 1994).

Os problemas advindos do uso intensivo dos agrotóxicos resultaram em uma rápida depreciação dos produtos no mercado, requerendo, por parte das empresas, maiores esforços para o desenvolvimento de novos produtos a fim de garantir o seu market-share. Por outro lado, encontrar novos ingredientes ativos tornou-se cada vez mais difícil (Hartnell 1996; Joly \& Lemarie 2001; Possas et al. 1996).

\section{GRÁFICO 2 - TAXA DE APROVEITAMENTO DE SUBSTÂNCIAS TESTADAS PARA CADA INGREDIENTE ATIVO COLOCADO NO MERCADO}

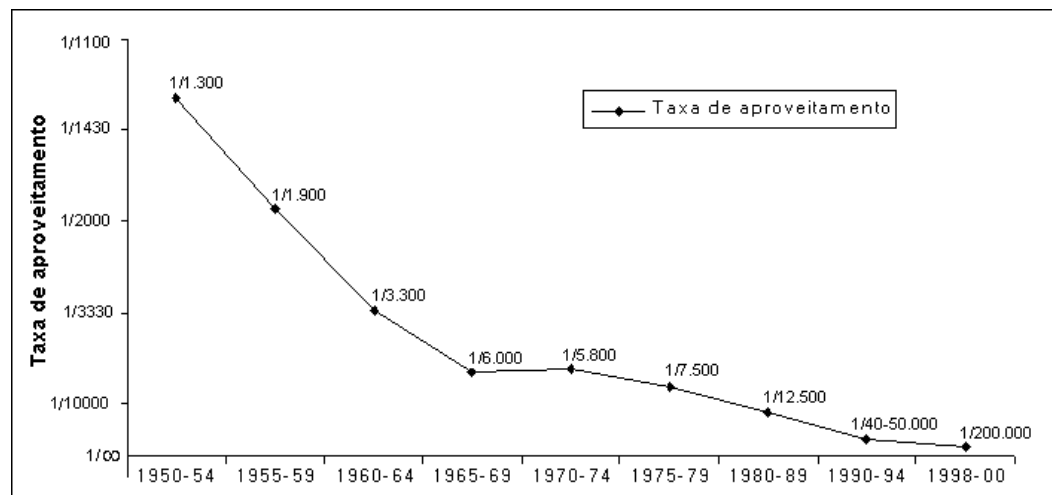

FONTE: Dados trabalhados a partir de STETTER, J. 1993. "Trends in the future development of pest and weed control: a industrial point view." Regulatory Toxicology and Pharmacology, 17: 346-70, JOLY, P. B. \& LEMARIE, S. 2002. "The technological trajectories of the agrochemical industry: change and continuity." Science and Public Policy, 29(4): 259-266.

Conforme observa-se no gráfico 2, enquanto que no final da década de 1950 a taxa de aproveitamento de substâncias testadas anualmente era de 1 para 1.900 , na década de 1980 essa taxa caiu de 1 para 12.500. E no final da década de 1990 o número de substâncias testadas, para cada 
ingrediente ativo colocado no mercado, era mais de cem vezes maior que em 1950.

A lucratividade das empresas de agrotóxicos passava, portanto, por uma fase de declínio, principalmente em função do aumento dos custos dos preços do petróleo que representa o principal insumo da indústria de agrotóxicos. A possibilidade de exploração comercial da biotecnologia passou então a ser uma oportunidade para as firmas de agrotóxicos manterem-se no mercado, seja por meio da diversificação das atividades (sementes), seja pela criação de produtos complementares ao uso dos agrotóxicos (sementes tolerantes a herbicidas), como será discutido a seguir (Joly \& Lemarie 2001; Possas et al. 1996; Tait et al. 2001).

\section{A agrobiotecnologia e a estratégia de diversificação das empresas do ramo químico}

A descoberta da técnica de DNA recombinante (rDNA) por Cohen e Boyer em 1973, que permitiu a união e transferência de genes entre organismos diferentes, constituiu a base de uma nova técnica de melhoramento genético vegetal e animal baseada na transgenia (Parayl 2003; Thompson 1986). Essa técnica representa um grande avanço no melhoramento genético de sementes em relação às técnicas convencionais. Enquanto que a técnica de melhoramento convencional consiste na seleção de melhores variedades obtidas a partir de cruzamento se-xual entre espécies diferentes (hibridização), que por vezes resulta em incorporação de características indesejáveis, a transgenia permite a inserção de genes (que podem não ser da mesma espécie ou família da planta receptora) correspondentes à característica que se deseja obter sem que haja cruzamento sexual. A transgenia representa, portanto, um melhoramento genético que, para alguns autores, é tido como preciso e rigoroso, reduzindo o tempo necessário para a obtenção de novas variedades (Lajolo \& Nutt 2003; Parayl 2002; Pengue 2000).

Na década de 1980, as empresas de agrotóxicos passaram a utilizar a engenharia genética em seus processos de produção de ingredientes ativos e a investir em pesquisas para o desenvolvimento de sementes geneticamente modificadas (Parayil 2002; Thompson 1986). Nesta época, a Monsanto Corporation (EUA), o Max Planck Institute for Plant Breeding (West Germany) e o Genetic Plant System (Bélgica) encontraram um método de criar plantas transgênicas utilizando a bactéria patogênica Agrobacterium tumefaciens, que funciona como um vetor de transferência de genes a partir da indução à produção de tumores. (Uzogara 2000; Rotili 2001; Rivas 2003). A primeira planta transgênica 
foi obtida em 1983, com a introdução de um gene codificante para a resistência à canamicina em plantas de fumo (Gander \& Marcelino 1997).

Durante a década de 1980, iniciou-se um movimento de diversificação de atividades de empresas da indústria de agrotóxicos para o ramo de sementes, em uma fase de reestruturação global decorrente do fim do boom de crescimento do pós-guerra. A crise dos mecanismos de financiamento da Revolução Verde (juros subsidiados) levou a dificuldades de se manter o nível de consumo de insumos agrícolas - até então crescente - reduzindo assim as vendas das empresas de agrotóxicos e de equipamentos (Assouline et al. 2002). Por outro lado, as promessas da biotecnologia representavam uma ameaça às empresas de insumos químicos, uma vez que havia a possibilidade de desenvolvimento de produtos com proteção vegetal genética, ou seja, sementes que dispensassem o uso de pesticidas (Ducos \& Joly 1988). Outro agravante para a crise que se desenhava na indústria química foi a criação de regulação ambiental, decorrente da preocupação com a degradação do meio ambiente, surgida na década de 1970. Esse fator implicou em aumentos adicionais nos custos de desenvolvimento e de comercialização de novas substâncias agroquímicas (Assouline et al. 2002; Den Hond 1998; Hartnell 1996).

Face a esses fatores, as empresas do ramo químico - sobretudo o segmento presente na atividade de produção de agrotóxicos - passaram a procurar alternativas para manterem-se no mercado, por meio de investimentos em biotecnologia para o desenvolvimento de sementes transgênicas. Para tanto, foram realizadas uma série de reestruturações organizacionais, fusões e aquisições de pequenas firmas de biotecnologia ou de empresas de sementes (Assouline et al. 2002; Ducos \& Joly 1988).

Esses novos grupos formaram-se em torno do que passou a ser denominado ciências da vida, ou seja, a exploração de sinergias entre os ramos agroquímico e farmacêutico (Assouline et al. 2002).

Early interpretations of the term 'life science' assumed that, by using biotechnology to gain a better understanding of the functioning of cells across a wide spectrum of species, there would be useful crossfertilization of ideas between the development of new drugs and new crop protection products. (Tait et al. 2002:255)

Grande parte das empresas que passaram a investir no desenvolvimento de sementes geneticamente modificadas na década de 1980 originaram-se desses grupos e apresentavam, até então, um nível de investimento em melhoramento genético vegetal tradicional relativamente 
pequeno ou nulo, como era o caso da Dekalb, Monsanto, Ciba-Geigy, DuPont e Calgene.

TABELA 1 - DESPESAS EM P\&D DE EMPRESAS SELECIONADAS DOS RAMOS DE SEMENTES E AGROTÓXICOS - 1988 (US\$ MILHÕES)

\begin{tabular}{l|c|c|c}
\hline \multirow{2}{*}{ EMPRESAS } & \multicolumn{2}{|c|}{ DESPESAS EM PESQUISA E DESENVOLVIMENTO } & \multirow{2}{*}{ ATIVIDADE PRINCIPAL } \\
\cline { 2 - 3 } & Melhoramento Tradicional & Biotecnologia Vegetal & EM 1985 \\
\hline Pioneer & 46 & 7 & Químicos \\
Sandoz & 41 & 16 & Químicos \\
Upjohn & 24 & 3 & Sementes \\
Limagrain & 22 & 5 & Químicos \\
ICI & 21 & 17 & Químicos \\
Shell & 19 & 3 & Sementes \\
KWS & 18 & 5 & Sementes \\
Dekalb-Pfizer & 16 & 6 & Químicos \\
Ciba-Geigy & 9 & 17 & Químicos \\
Monsanto & 1 & 15 & Químicos \\
Du Pont & 0 & 20 & Químicos \\
Enimont & 0 & 15 & $?$ \\
Agrigenetics & 6 & 12 & $?$ \\
Maribo & 7 & 12 & $?$ \\
Calgene & 1 & 10 & $?$ \\
DNAP & 1 & 11 & \\
\hline
\end{tabular}

FONTE: Dados trabalhados a partir de: JUNNE, G. "O ritmo das grandes corporações em biotecnologia agrícola.” Ensaios FEE, Porto Alegre, 13(2): 393-406, 1992; DUCOS, C. \& JOLY, P.B. Les biotechnologies. Paris: Édition La Decouvert, 1988.

NOTAS: ${ }^{1}$ Comprada pela Monsanto (Assouline et al. 2002)

A tabela 1 ilustra a estratégia de diversificação das empresas do ramo químico no mercado de sementes, no final dos anos 80, por meio do desenvolvimento da biotecnologia vegetal. Com exceção da Sandoz e da ICI, presentes de forma expressiva no melhoramento tradicional e cujo nível de investimento em P\&D na área de biotecnologia vegetal foi dos mais elevados, as principais empresas que investiram em melhoramento, baseado na engenharia genética, migraram dos ramos químico e farmacêutico. A lógica de mercado que se desenvolveu na criação de novos produtos foi decorrente dessa redefinição das estratégias de crescimento das empresas.

Para essas empresas, identificam-se duas trajetórias tecnológicas, no que é considerado a primeira geração de OGM: i) desenvolvimento de proteção genética, ou seja, sementes resistentes a insetos e outras pragas, eliminando o uso de pesticidas; e ii) continuidade da proteção química, ou seja, sementes tolerantes a determinados agrotóxicos que desempenham papel complementar a alguns pesticidas específicos, como o caso das sementes tolerantes a herbicidas (Assouline et al. 2001; Ducos \& Joly 1988). Dois tipos de sementes concretizam essas trajetórias: 
a) as variedades resistentes a insetos - nas quais foi inserido um gene da bactéria Bacillus thuringiensis (Bt) - que emitem uma substância tóxica aos insetos quando estes atacam as folhas. A primeira variedade resistente a insetos desenvolvida foi para a cultura do tabaco, em 1986 nos EUA, mas atualmente as principais espécies com esta característica são o milho e o algodão, que juntos representam cerca de $17 \%$ das lavouras transgênicas em 2002 (Ducos \& Joly 1988; James 2002);

b) as variedades tolerantes a herbicidas, cujo gene inserido também é de uma bactéria que permite a resistência da planta ao ingrediente ativo do herbicida. A principal espécie tolerante a herbicida é a soja, com 62\% das lavouras transgênicas em 2002 (Ducos \& Joly 1988; James 2002);

Ducos e Joly (1988:61-62) sintetizam as expectativas dos ganhos econômicos advindos dessa tecnologia :

La résistance aux herbicides offre un potentiel d'extension du marché que le cabinet américain L. W. Teweless estime à plus de 2 milliards de dollars en l'an 2000. De plus, elle permettrait d'amortir les coûts de développement des nouvelles molécules herbicides (estimés à 40 millions de dollars en moyenne) sur des marchés plus larges. Les calculs effectués selon les paramètres techniques actuels montrent en effet que la tolérance du soja à l'atrazine permettrait une augmentation des ventes annuelles de Ciba Geigy de 120 millions de dollars; l'extension des plantes résistantes au Roundup (premier herbicide mondial) pourrait accroître les ventes de Monsanto de 150 millions de dollars; le travaux de Plant Genetic System (en Belgique) sur l'herbicide Basta de Hoechst permettraient d'augmenter les ventes de 200 millions de dollars.

Tait, Chataway e Wield (2002:256) chamaram a atenção para o antagonismo que existia inicialmente entre as duas trajetórias tecnológicas:

Some interactions between agrochemicals and biotechnology could be antagonistic rather than synergistic from the company's point of view, especially for the inputs traits developed in the first generation of GM crops. GM-based disease and pest resistance would diminish the market for insecticides and fungicides. Herbicide resistance, on the other hand, reinforces the market potential of some herbicides, and no GM developments are currently envisaged that could substitute for herbicides. (Tait et al. 2002:256)

Esse antagonismo parece, no entanto, estar sendo superado pelo que seria uma segunda geração de OGM, na qual as empresas buscam justamente a combinação dessas características (Monsanto 2006). Uma ou- 
tra característica que começa a ser anunciada pelas empresas e por pesquisadores é o desenvolvimento de plantas que acentuam determinadas substâncias nutricionais desejáveis, como o Ômega 3 ou a vitamina E, ou ainda a redução de substâncias consideradas indesejáveis como o colesterol em oleaginosas (Borém 2006).

As primeiras sementes geneticamente modificadas tiveram a comercialização autorizada nos EUA a partir de meados dos anos 90, conforme se observa no quadro 1.

\section{QUADRO 1 - AUTORIZAÇÃO PARA COMERCIALIZAÇÃO DE SEMENTES GENETICAMENTE MODIFICADAS NOS EUA}

\begin{tabular}{|l|c|c|c|c|}
\hline PRODUTO & EMPRESA & CARACTERÍSTICA & NOME COMERCIAL & $\begin{array}{c}\text { ANO DE } \\
\text { APROVAÇÃO }\end{array}$ \\
\hline Milho & Ciba & Proteção contra insetos & Maximizer & 1995 \\
Milho & Mycogen & Proteção contra insetos & Nature Gard & 1995 \\
Milho & Sandoz/Northrup King & Proteção contra insetos & Desconhecido & 1995 \\
Algodão & Calgene/Rhone-Poulenc & Resistência a herbicida & BXN Cotton & 1995 \\
Algodão & Monsanto & Proteção contra insetos & Bollgad & 1995 \\
Algodão & Monsanto & Resistência a herbicida & Roundup Ready & 1996 \\
Batata & Monsanto & Proteção contra insetos & New Leaf & 1995 \\
Soja & Monsanto & Resistência a herbicida & Roundup Ready & 1995 \\
Tomate & Agritopa & Retarda alteração & Desconhecido & 1996 \\
Tomate & Calgene & Retarda alteração & Flavr Savr & 1994 \\
Tomate & DNA Plant Technology & Retarda alteração & Endless Summer & 1995 \\
Tomate & Monsanto & Retarda alteração & Desconhecido & 1995 \\
Tomate & Zeneca/Peto Seed & Retarda alteração & Desconhecido & 1995 \\
\hline
\end{tabular}

FONTE: Agribusiness, Dez/1996. In: PELAZ, V. \& PONCENT, C. "Estratégias industriais e mudança técnica: o processo de diversificação da Monsanto.” História Econômica e História de Empresas, 2(2): 139-60, 1999.

Dentre os principais produtos liberados para comercialização até 1996, cerca de $38 \%$ tinham como característica a resistência a insetos, enquanto que apenas $23 \%$ tinham como característica a tolerância a herbicidas. Portanto, até esse momento predominava a trajetória de eliminação de insumos químicos. A difusão dessas sementes em nível mundial modifica essa configuração.

As primeiras lavouras transgênicas foram cultivadas a partir de 1996. Desde então, a área global de cultivos transgênicos cresceu mais de cinqüenta vezes: de 1,7 milhão de hectares em 1996 para mais de 100 milhões de hectares em 2006 (James 2006). As principais espécies cultivadas são soja, milho, algodão e canola, e as principais características incorporadas nestas espécies são resistência a insetos e tolerância a herbicidas.

Em 2005, predominaram as lavouras tolerantes a herbicidas, que representavam cerca de $71 \%$ da área global. Em segundo lugar, vêm as variedades resistentes a insetos, com aproximadamente $18 \%$ da área global. As demais variedades (resistência a vírus, fungos, etc.) representam 11\% da área global (James 2005). 
Entre as lavouras transgênicas dominantes, a soja tolerante a herbicida é a predominante, com $60 \%$ da área global de transgênicos, seguida do milho Bt (24\%), algodão (11\%) e canola (8\%) (James 2005). A rápida difusão dessas lavouras, em nível mundial, indica a prioridade de P\&D atribuída às principais culturas de consumo pelas empresas de sementes, em função do grande potencial de expansão desses mercados.

A adoção das sementes geneticamente modificadas está baseada em promessas de benefícios agronômicos e econômicos, principalmente em termos de redução de custos na utilização de agrotóxicos (Nielsen et al. 2001). A comprovação desse tipo de informação tem sido muito polêmica, na medida em que têm sido publicados estudos com resultados antagônicos, ora indicando uma redução ora um aumento do uso dessas substâncias.

Fernandez-Cornejo \& McBride (2000) publicaram as primeiras estimativas da evolução do uso de agrotóxicos de variedades de soja e de algodão GM, resistentes ao herbicida glifosato, nos primeiros anos de sua adoção em larga escala nos EUA (1996-1998). Os estudos indicaram uma redução de cerca de $10 \%$ no uso de todos os herbicidas utilizados em relação às variedades convencionais, enquanto que o uso do glifosato teria aumentado em $250 \%$. Já o estudo organizado por Sujatha \& Blumenthal (2004) para a safra de 2003, em 11 culturas GM, indicou uma redução na quantidade de agrotóxicos utilizada de 46,4 milhões de libras em relação à safra anterior. Essa redução teria representado uma economia da ordem de US\$ 1,5 bilhão. E a redução do uso de agrotóxicos em variedades GM resistentes a herbicidas (soja, milho, algodão, canola) teria sido 5,5 vezes superior do que nas variedades GM resistentes a insetos.

Por outro lado, Benbrook (2004) fez uma estimativa da evolução do uso de agrotóxicos de variedades GM tolerantes a herbicidas e resistentes a insetos, em relação às variedades não-GM, nos EUA, de 1996 a 2004. Segundo essa pesquisa, para as variedades GM resistentes a insetos o uso de agrotóxicos teria diminuído em torno de 15,6 milhões de libras, nesses nove anos, enquanto que para as variedades GM tolerantes a herbicida, o volume de agrotóxicos aplicados nas culturas de milho, soja e algodão, teria aumentado em 138 milhões de libras. Nessas variedades GM resistentes a herbicidas, teria havido uma redução no uso de agrotóxicos nos três ou quatro primeiros anos da adoção dessas culturas, com uma acentuada inversão dessa tendência nos últimos anos, à qual atribui-se o efeito do aumento da resistência das ervas daninhas devido ao uso continuado de um mesmo tipo de herbicida.

A carência de estudos que apresentem séries históricas de pelo menos cinco anos consecutivos do desempenho agronômico dessas variedades GM, como a realizada por Benbrook (2004), é um dos principais 
fatores que dificultam tirar conclusões mais consistentes sobre a confirmação dos tão propalados benefícios agronômicos da transgenia. A inexistência desses estudos deixa espaço para o intenso trabalho de convencimento (marketing) dos produtores agrícolas realizado pelas empresas de sementes GM (Pelaez et al. 2004).

Independente da existência de resultados de pesquisas científicas sobre o desempenho agronômico dessas variedades GM, o fato de as principais empresas de agrotóxicos investirem maciçamente na produção de sementes GM resistentes a herbicidas já indica uma estratégia de (re)valorização de seus principais ativos, uma vez que as vendas de pesticidas representam a maior parte da fonte de receitas destas empresas, conforme se observa no gráfico 3 (Chatway \& Tait 2000; Pelaez \& Poncent 1999). Entre as dez principais empresas de sementes do mundo, que detêm aproximadamente $90 \%$ do mercado mundial, as três principais (Pioneer-Dupont, Monsanto e Syngenta) têm como principal atividade a produção de agrotóxicos (Assouline et al. 1999; Chataway \& Tait 2000).

\section{GRÁFICO 3 - VENDAS DOS GRUPOS DE AGROTÓXICOS E SEMENTES - 2002 (US\$ BILHÕES)}

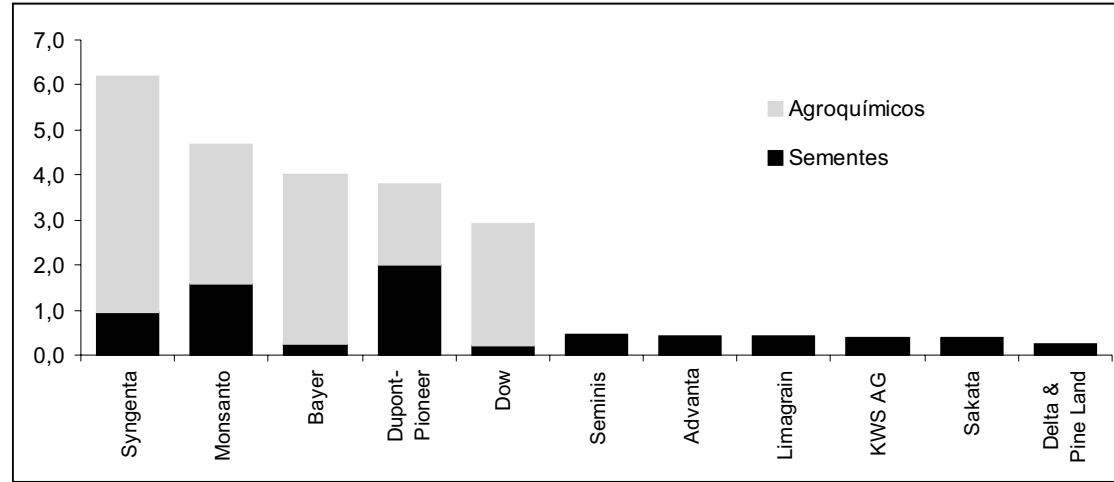

FONTE: ETC GROUP. Oligopoly, Inc.: concentration in corporate power 2003. ETC Communiqué, 82, 2003.

Em 2004, a Dupont-Pioneer controlava 10\% do mercado mundial de sementes (GM e não-GM), a Monsanto $9 \%$ e a Syngenta 5\% (Unctad 2006). No que tange ao mercado de sementes GM, a Monsanto lidera, sendo proprietária de 53\% dos OGM aprovados para comercialização nos EUA, entre 1992 e 2005, o que corresponde a 53\% da área cultivada com culturas GM no mundo (James 2006). Em 1999, a Monsanto estimava que cerca de 87\% (34,8 milhões de hectares) da área mundial de lavouras transgênicas eram cultivadas com suas sementes (Monsanto 2001). 
Como observam Pelaez \& Poncet (1999:143), a atuação da Monsanto no ramo de sementes e da engenharia genética “(...) tem sido motivada fundamentalmente pelo interesse em aumentar o espectro de utilização de seu principal produto, o Roundup." Esse agrotóxico, descoberto na década de 1970, tornou-se o herbicida mais vendido no mundo e a principal fonte de receita da empresa. Criar sementes geneticamente modificadas como produto complementar ao herbicida foi uma estratégia que garantiu a extensão dos ganhos extraordinários de monopólio obtidos com o Roundup, cuja patente expirou no ano 2000.

A dinâmica da mudança tecnológica no campo da agrobiotecnologia, que ora se observa, resulta, portanto, da combinação de um conjunto de fatores. Ela ocorre não apenas em função da evolução do conhecimento científico e tecnológico, mas também da dinâmica de concorrência dos respectivos mercados, bem como da lógica de valorização dos ativos das empresas oriundas principalmente do ramo químico.

\section{Conclusões}

A crise do paradigma tecnológico caracterizado pela Revolução Verde, em termos de seus impactos ambientais e da redução da produtividade marginal, impôs limites cada vez maiores à expansão das empresas de sementes e de agrotóxicos. Ao mesmo tempo, a redução de produtividade da atividade de P\&D de novas substâncias químicas tem comprometido os níveis de rentabilidade dessas empresas. Este fato é ainda agravado pelo esgotamento da validade das patentes de agrotóxicos, cujas vendas tendem a ser cada vez mais ameaçadas pela concorrência com os produtos genéricos.

As possibilidades de combinar técnicas de engenharia genética no desenvolvimento de plantas mais resistentes aos defensivos químicos, às pragas e aos insetos, abriram novas perspectivas de expansão do capital das empresas do ramo agroquímico. O movimento de diversificação dessas empresas para o ramo de sementes reflete justamente uma estratégia de crescimento externo, baseado nas perspectivas identificadas pelo que seria um novo paradigma de produção agrícola, substituindo as técnicas de melhoramento convencional pela transgenia. Apesar das promessas daí advindas de redução do uso intensivo de agrotóxicos, que marca o modelo de produção da Revolução Verde, a trajetória adotada pelas empresas tem privilegiado o desenvolvimento de sementes resistentes a esses produtos, com o respectivo aumento de seu consumo, corroborando a continuidade do paradigma já instalado. Ou seja, a biotecnologia não representaria ainda um fator-chave capaz de substituir o anterior (insumos químicos), mas sim uma técnica complementar capaz de garantir a continuidade do modelo de produção já instalado. 
A adoção desse tipo de trajetória tecnológica é coerente com as estratégias das referidas empresas de valorização de seus principais ativos: os produtos agrotóxicos. Tais estratégias podem, por um lado, indicar uma fase pré-paradigmática de transição, na qual as empresas ainda procuram esgotar as possibilidades comerciais de seus antigos investimentos e na qual o estado-da-arte do novo modelo ainda não oferece as alternativas de produção prometidas. Por outro lado, tais estratégias podem levar à retomada do ciclo anterior de expansão das empresas, reforçando assim as características estruturais de produção e de apropriação da Revolução Verde.

A evolução da atual trajetória irá, enfim, determinar as possibilidades de consolidação do potencial de aumento de produtividade e de rentabilidade prometidos pela biotecnologia, o qual seria capaz de gerar um processo de reestruturação das variáveis-chave de ambos os modelos. Tal processo dependerá não apenas da evolução do conhecimento científico e tecnológico da área, mas também dos aspectos institucionais (de regulação e de aceitação do público consumidor) que condicionam a expansão dessa alternativa tecnológica ainda muito controvertida.

\section{Referências}

ANDERSEN, B. (1998). "The evolution of technological trajectories: 18901990." Structural Change and Economic Dynamics 9(1): 5-34.

ASSOULINE, G. \& JOLY, P. \& LEMARIE, S. (2003). "Interactions between public policies and company innovation strategies: overview of the company monographs." PITA Project: policy influences on technology for agriculture: chemicals, biotechnology and seeds. URL: http:// technology.open.ac.uk/ cts/pita/AnnC1-Over-monographs.pdf. Acesso em: 27 de setembro de 2003 .

ASSOULINE, G. \& JOLY, P. \& LEMARIE, S. (2002). "Plant biotechnology and agricultural supply industry restructuring." International Journal of Biotechnology 4(2/3): 194-210.

BEAUD, M. (1994). História do capitalismo: de 1500 até nossos dias. 4. ed. São Paulo: Brasiliense.

BENBROOK, C. M. (2004). "Genetically engineered crops and pesticide use in the United States: the first nine years.” Biotech Infonet, Technical Paper 9 .

BIJMAN, J. JOLY, P-B. (2001) "Innovation challenges for the European agbiotech industry." AgBioForum 4(1): 4-13. URL: http://www.agbioforum.org/v4n1/ v4n1ao2-bijman.pdf. Acesso em: 10 de janeiro de 2004.

BIONDI, L. \& GALLI, R. (1992). "Technological trajectories.” Futures 24(6): 580-591.

BORÉM, A. (1998). Melhoramento de plantas. 2. ed. Viçosa: UFV. 
BORÉM, A. (2006). Nova geração de produtos da biotecnologia. URL: http:// www.anbio.org.br/artigos/arto6.htm. Acesso em: 12 de dezembro de 2006.

BRUM, A. (1988). Modernização da agricultura: trigo e soja. Petrópolis: Vozes.

BUTTEL, F. H. (1992). "Ideologia e tecnologia agrícolas no final do século XX: biotecnologia como símbolo e substância.” Porto Alegre. Ensaios FEE 14: 303-322.

CHATAWAY, J. \& TAIT, J. (2003). "Monsanto monograph." PITA Project: policy influences on technology for agriculture: chemicals, biotechnology and seeds. URL: http://technology.open.ac.uk/cts/pita/AnnC1-Overmonographs.pdf. Acesso em: 27 de setembro de 2003.

DEN HOND, F. (1998). "On the structuring of variation in innovation processes: a case of new product development in the crop protection industry." Research Policy 27: 346-367.

DERRY, T. K. \& WILLIANS, T. K. D. (1977). Historia de la tecnologia: desde 1750 hasta 190o. v. 3. Madri: Siglo Veintiuno Editores.

DOSI, G. (1982). “Technological paradigms and technological trajectories: a suggested interpretation of the determinants and directions of technical change." Research Policy 11(2): 147-162.

DOSI, G. (1988). "Sources, procedures and microeconomic effects of innovation." Journal of Economic Literature 26: 1120-1171.

DOSI, G. (1993). "Algumas questões sobre a inovação biotecnológica.” Porto Alegre. Ensaios FEE 14(1): 368-371.

DUCOS, C. \& JOLY, P. B. (1988). Les biotechnologies. Paris: Édition la Decouverte.

EVENSON, R. E.; GOLLIN, D. (2002). "The Green Revolution: an end of century perspective." Economics at Williams College. URL: ht tp: / / www.williams.edu/Economics/wpGollin\% 20 The \% 20 Green\%20Revolution.pdf. Acesso em: 10 de setembro de 2003.

ETC GROUP (2003). "Oligopoly, Inc.: concentration in corporate power 2003.” ETC Communiqué 82. URL: http://www.etcgroup.org. Acesso em: 19 de janeiro de 2003.

FERNANDEZ-CORNEJO, J. \& McBRIDE, W. D. (2000). "Genetically engineered crops for pest management in U.S. agriculture: farm-level effects." Economic Research Service 786, U.S. Department of Agriculture.

FERRARI, M. A. R. \& PAULA, T. H. P. (1999). "Inovação tecnológica e dinâmica econômica: uma síntese de algumas contribuições evolucionistas.” Revista de Economia UFPR 23: 139-157.

FREEMAN, C. (1984). "Prometheus unbound." Futures 16(5): 494-507. URL: http://www.sciencedirect.com/science. Acesso em: 12 de junho de 2003.

FREEMAN, C. \& PEREZ, C. (1988). "Structural crises of adjustment: business cycles and investment behavior". In DOSI, G. et al. Technical change and economic theory. Londres: Pinter Publishers, 1988, p. 38-66.

GOODMAN, D. \& SORJ, B. \& WILKINSON, J. (1990). Da lavoura às 
biotecnologias. São Paulo: Campus.

GOODMAN, D. \& REDCLIFT, M. (1991). Refashioning nature: food, ecology and culture. Londres: Routledge.

HARTNELL, G. (1996). "The innovation of agrochemicals: regulation and patent protection”. Research Policy 25(3): 379-395.

JAMES, C. (2005). "Prévia: situação global das lavouras transgênicas comercializadas em 2005". ISAAA: Ithaca (NY). (ISAAA Briefs, n. 34). URL: http://www.isaa.org. Acesso em: 15 de janeiro de 2007.

JAMES, C. (2006). Global status of commercialized biotech/GM Crops: 2006. ISAAA: Ithaca (NY). (ISAAA Briefs, n. 35). URL: http://www.isaaa.org/ Resources/Publications/briefs/35/executivesummary/default.html. Acesso em: 15 de janeiro de 2007.

JOLY, P. B. \& LEMARIE, S. (2002). "The technological trajectories of the agrochemical industry: change and continuity." Science and Public Policy 29(4): 259-266.

JOLY, P. B. \& LOOZE, M. A. (1996). "An analysis of innovation strategies and industrial differentiation through patent applications: the case of plant biotechnology.” Research Policy 25(7): 1027-1046.

JUNNE, G. (1992). "O ritmo das grandes corporações em biotecnologia agrícola." Porto Alegre. Ensaios FEE 13(2): 393-406.

KUHN, T. (1975). A estrutura das revoluções científicas. São Paulo: Pesrpectiva.

MONSANTO Press Release. (2000). Monsanto Reports 1999: fourth-quarter and full-year results. St. Louis: Monsanto.

MONSANTO. (2006). "Produtores norte-americanos já contam com milho GM com três características agregadas”. URL: http://209.85.165. 104/search?q=cache:XvuUbhzVBUwJ:www. monsanto.com.br/sala/br/. Acesso em: 18 de dezembro de 2006.

MUIR, P. (1998). “The Green Revolution”. Oregon State University. URL: http:/ /oregonstate.edu/instruction/bi301/greenrev.htm. Acesso em: 05 de novembro de 2003.

OFFICE OF TECHNOLOGY ASSESSMENT OTA. (1991). "Biotechnology in a global economy". Washington, DC: U.S. Government Printing Office. URL: http://www.wws.princeton.edu/cgi-bin/byteserv.prl/ ota/disk1/1991/ 9110/911010.PDF. Acesso em: 30 de novembro de 2003.

PARAYIL, G. (2002). "Mapping technological trajectories of the green revolution and the gene revolution from modernization to globalization." Research Policy 32(6): 971-990.

PELAEZ, V. M. P. \& PONCET, C. (1999). "Estratégias industriais e mudança técnica: uma análise do processo de diversificação da Monsanto." História Econômica \& História de Empresas II.2: 139-160.

PEREZ, C. (1992). "Cámbio técnico, reestructuración competitiva y reforma institucional en los países en desarrollo.” El Trimestre Económico 61: 2364 . 
PEREZ, C. (1983). "Structural change and assimilation of new technologies in the economic and social systems." Futures 15(5): 357-375.

PRETTY, J. N. (1995). Regenerating agriculture: policies and practice for sustainability and self-reliance. Londres: Earthscan.

RURAL ADVANCEMENT FOUNDATION INTERNATIONAL - RAFI. (2000). "Speed bump or blow-out for GM seeds?: stalling markets, taco debacle \& biotech bail out. RAFI". URL: http://www.etcgroup.org/documents/ geno_speedbump.pdf. Acesso em: 30 de dezembro de 2003.

STETTER, J. (1993). "Trends in the future development of pest and weed control: a industrial point view." Regulatory Toxicology and Pharmacology 17(3): 346-370.

SUJATHA, S. \& BLUMENTHAL, E. (October, 2004). "Impacts on U.S. agriculture of biotechnology-derived crops planted in 2003." National Center for Food and Agricultural Policy, Washington D. C.

TAIT, J. \& CHATAWAY, J. \& WIELD, D. (2002). "The life science industry sector: evolution of agro-biotechnology in Europe." Science and Public Policy 29(4): 253-258.

UNCTAD - United Nations Conference on Trade and Development. (2006). Tracking the trend towards market concentration: the case of the agricultural input industry.

USDA - United States Department of Agricultural. (2006). "Agricultural Resources and Environmental Indicators, 2006". URL: http:// www.ers.usda.gov/publications/arei/eib16/. Acesso em: 10 de janeiro de 2007.

Recebido em: 23 maio 2006 Aceite em: 30 jun. 2006 